\title{
Bone Scan for Baseline Staging in Invasive Breast Cancer at the Time of Primary Presentation
}

\author{
Fabio Puglisia, ${ }^{a} \quad$ Claudia Andreetta ${ }^{a}$ b $\quad$ Gianpiero Fasola $^{b} \quad$ Elena Cattaruzzi ${ }^{c} \quad$ Onelio Geattic \\ a Breast Unit, \\ b Department of Oncology, \\ ${ }^{c}$ Department of Nuclear Medicine, University Hospital of Udine, Italy
}

\section{Key Words}

Breast cancer · Staging · Bone scan

\begin{abstract}
Summary
99mTechnetium-labeled methylene diphosphonate bone scan (BS) is the most commonly used imaging test to screen for skeletal metastases in patients with breast cancer. Since its introduction into clinical practice, a large number of studies have been conducted to explore the role of $B S$ in the baseline staging work-up at the time of breast cancer diagnosis. Even though the policy of offering preoperative or perioperative BS is still widely diffuse, a lot of evidence in the literature suggests that routine BS examinations are not cost-effective and should be recommended in selected cases only. Based on current guidelines, the use of BS as a staging procedure is considered appropriate in patients with a high pre-test probability (prevalence) of bone metastases. This category is represented by patients with newly diagnosed high-risk breast cancer (i.e. pN2 or T4/pT4) or with symptoms or laboratory signs suspicious for bone involvement.
\end{abstract}

\section{Introduction}

Baseline preoperative staging has been traditionally proposed to patients with newly diagnosed invasive breast carcinoma (BC) in order to detect asymptomatic preclinical distant metastases $[1,2]$. The diagnostic work-up is usually performed

\author{
Schlüsselwörter \\ Brustkrebs · Staging · Skelettszintigraphie
}

\section{Zusammenfassung}

99mTechnetium-markierte Methylendiphosphonat-Skelettszintigraphie ist das am häufigsten verwendete bildgebende Verfahren zur Diagnose von Knochenmetastasen bei Brustkrebspatienten. Seit der Einführung der Skelettszintigraphie in die klinische Praxis sind eine Vielzahl von Studien zur Untersuchung ihrer Rolle als Baseline-Staging-Verfahren zum Zeitpunkt der Brustkrebsdiagnose durchgeführt worden. Obwohl die Strategie bezüglich des Angebots preoperativer oder perioperativer Skelettszintigraphie noch immer sehr verschwommen ist, gibt es in der Literatur eine Vielzahl von Hinweisen, dass routinemäßige Skelettszintigraphie nicht kosteneffektiv ist und nur in spezifischen Fällen vorgeschlagen werden sollte. Basierend auf aktuellen Richtlinien ist die Anwendung der Skelettszintigraphie als Staging-Verfahren angebracht bei Patienten, welche mit hoher Wahrscheinlichkeit (Prävalenz) Knochenmetastasen aufweisen. Diese Kategorie besteht aus Patienten mit neu diagnostiziertem Hochrisiko-Brustkrebs (pN2 or T4/pT4) bzw. mit Symptomen oder Laborergebnissen, die auf Knochenbeteiligung hinweisen.

\begin{tabular}{ll}
\hline KARGER & @ 2007 S. Karger GmbH, Freiburg \\
Fax +4976145207 14 & Accessible online at: \\
$\begin{array}{l}\text { E-mail Information@Karger.de } \\
\text { www.karger.com }\end{array}$ & www.karger.com/brc
\end{tabular}

by chest X-ray, liver ultrasound, and bone scan (BS). In addition, depending on the results of these tests, complementary imaging techniques such as plain radiography (XR), computed tomography (CT), magnetic resonance imaging (MRI), and 2[fluorine-18]fluoro-2-deoxy-D-glucose ( ${ }^{18} \mathrm{~F}$ FDG) positron emission tomography (PET) can also be suggested. The main 
Fig. 1. Whole body bone scan showing diffuse multifocal metastatic disease.

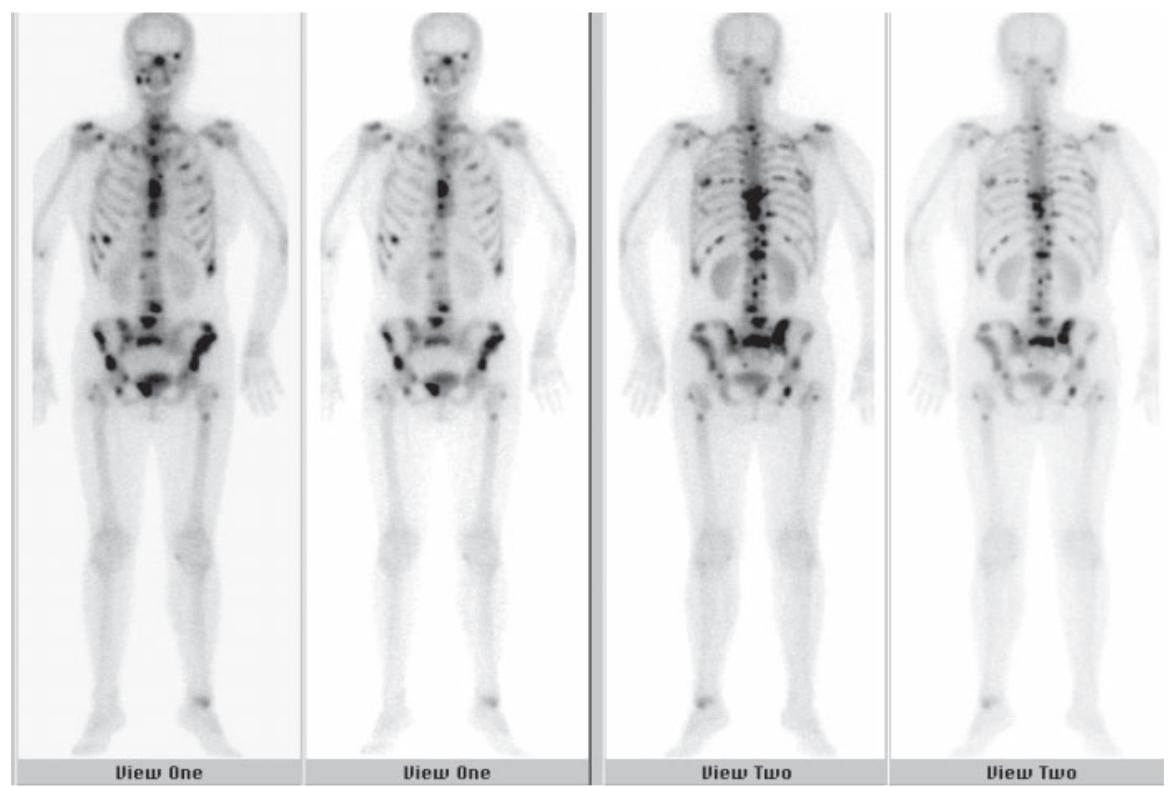

goal of staging investigations has been considered the identification, among asymptomatic patients, of those with or without distant metastases in order to estimate the prognosis and tailor the treatment accordingly [3]. However, the policy of proposing staging tests routinely, although still widely adopted, has been questioned. To date, in fact, no data exist supporting that the early treatment of patients receiving a diagnosis of metastases from BC before clinical manifestations is associated with better outcome than treatment of symptomatic patients. On the contrary, a lot of evidence in the literature suggested that a complete staging procedure is often unnecessary and uselessly expensive, especially outside of clinical trials [4-14]. In particular, several authors have argued against routine baseline imaging evaluations asserting that they are not cost-effective because of the low pre-test probability (i.e. prevalence) of metastases in asymptomatic patients with apparently early disease at the time of primary presentation.

This review, through a structured MEDLINE search of English-language peer-reviewed journals, critically analyzes the value of $\mathrm{BS}$ in the clinical management of patients with newly diagnosed invasive BC. However, the different designs and definitions of 'gold standard' among reported studies together with the long interval of time (more than 30 years) elapsed between oldest and most recent publications, make it arduous to compare results from the literature and preclude reliable meta-analysis of quantitative data.

\section{Bone Metastases in Breast Cancer}

Metastatic spread from BC can involve a variety of organs, including bone, liver, and lungs. Bone represents the most common site of metastases from $\mathrm{BC}$ with a prevalence that increases with the stage of tumor $[14,15]$. Up to half of bone metastases from BC shows a predominance of osteoclastic activity, but purely osteoblastic or mixed patterns may also be observed. This classification in osteolytic and osteoblastic lesions actually describes two extremes of a continuum in which dysregulation of the normal bone remodeling process occurs [16]. The most frequent sites of skeletal spread reflect the distribution of red bone marrow, and include the vertebrae (highly vascularized and containing $75 \%$ of the body's red marrow) and the pelvis, followed by ribs, skull, and the proximal long bones $[17,18]$. A great deal of literature is available on the mechanism of cancer dissemination to bone. Bone localization of $\mathrm{BC}$ derives from the hematogenous dissemination of cancer cells through a complex interaction between tumor cells and bone tissue. Different vascular networks have been proposed to be involved in tumor spread, such as a link between Batson's system and the azygos, hemi-azygos, and the internal mammary systems, via thoracic wall veins $[19,20]$. A peculiar dissemination through a pathological internal mammary chain has to be considered when sternum involvement is detected [21]. Direct lymphatic migration to bone usually does not occur, even though metastatic lymph nodes can occasionally erode into adjacent bone structures [20].

\section{Bone Scan}

\section{Technique}

99m Technetium-labeled diphosphonates (methylene diphosphonate, 99mTc-MDP, or hydroxymethylene diphosphonate, $\left.{ }^{99 m} \mathrm{Tc}-\mathrm{HDP}\right) \mathrm{BS}$ is the most commonly used imaging test when screening for skeletal metastases of BC $[22,23]$. Essentially, after intravenous injection, the radiopharmaceutical rapidly binds to osteoblastic cells of normal bone surface and, by the same way, reveals sites of increased osteoblastic metabolism 
Fig. 2. Left Posterior view of MDP bone scan (dual intensity) showing minor irregularities in the spine without any significant focal uptake, in particular at the level of the first dorsal vertebral bodies (see arrows). Right ${ }^{18}$ F FDG PET-CT of the same patient, showing intense focal uptake of the radiopharmaceutical corresponding to a well definite lytic area in the vertebral body (transverse views: top left PET; bottom left CT; right PET-CT fused image) (see arrows).
Fig. 3. Top Anterior and posterior views of MDP bone scan (dual intensity), showing definite focal uptake in right and left ileum, L5 and sacrum (see arrows). Bottom ${ }^{18}$ F FDG PET-CT of the same patient, showing no relevant uptake of the radiopharmaceutical in the left sacrum and both ileum where it is clearly seen an increased bone density (transverse views: top left PET; bottom left CT; right PET-CT fused image) (see arrows).
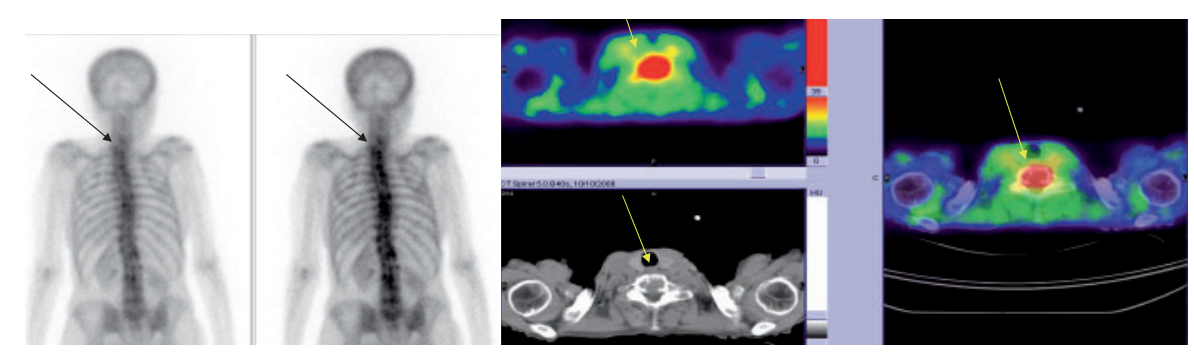
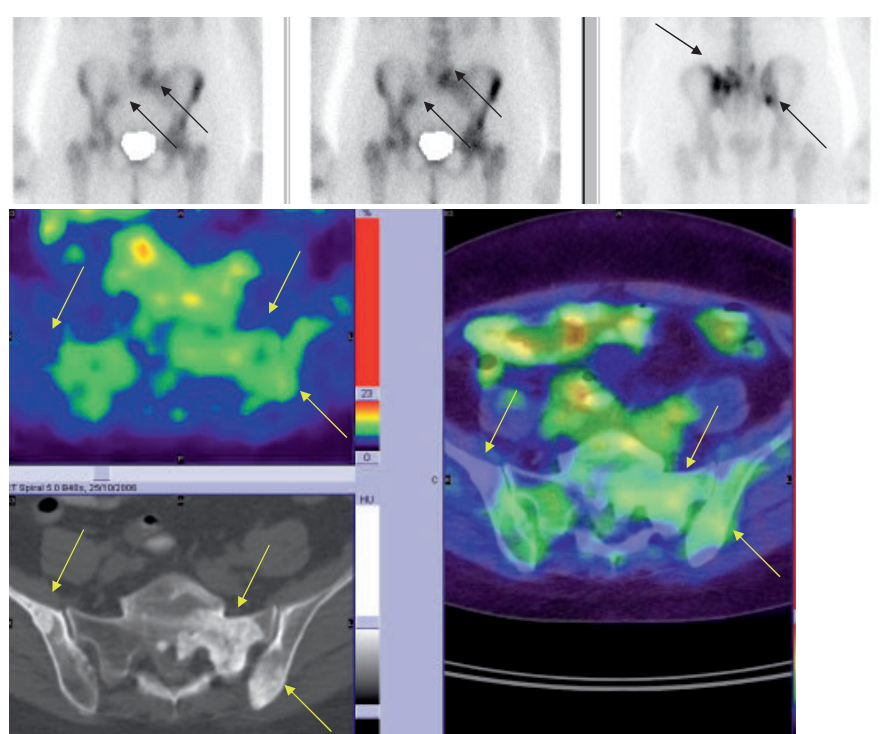

around neoplastic cells that have reached the bone. Usually, anterior and posterior whole body scans and, when necessary, additional planar views or segmental single photon emission computed tomography (SPECT) images are carried out with differently equipped gamma-cameras. Sites of bone disease, characterized by high vascularity and osteoblastic activity, appear as areas of increased uptake of ${ }^{99 \mathrm{~m}} \mathrm{Tc}$-phosphonate, called 'hot spots' (fig. 1).

\section{Diagnostic Accuracy of Bone Scan and Comparison with Other Imaging Modalities}

In 2004, Hamaoka et al. [18] conducted a literature review on the role of bone imaging in $\mathrm{BC}$ reporting a great variability in sensitivity and specificity of the different tests. Level II-III of evidence indicated that the sensitivity of BS ranges from 62 to $100 \%$ and the specificity from 78 to $100 \%$ [18]. Despite its inferior spatial resolution compared to other imaging techniques, BS could easily detect also small lesions if there is an intensive osteoblastic reparative response [24].

Due to its high sensitivity and relatively low cost (approximately $€ 140$ in Italy), together with moderate radiation burden and limited work time required to complete the study, BS is considered the first choice for screening of bone metastases in $\mathrm{BC}$ patients. However, since ${ }^{99 \mathrm{~m}} \mathrm{Tc}$-phosphonates are radio- pharmaceuticals with osteotropic but not specific oncotropic properties, several other non-malignant conditions of increased bone turnover (trauma, arthritis, infections, some metabolic diseases, etc.), can cause misleading interpretations due to a pattern similar to that of metastatic disease. In addition, in older patients with $\mathrm{BC}$, the specificity of BS may be also inferior, due to the higher prevalence of skeletal degenerative disease in this age-specific patient population.

Occasionally, even when the disease has spread to the bones, $\mathrm{BS}$ is not able to detect any abnormality (false negative results) because of the presence of avascular lesions and/or slow bone turnover. In addition, similarly to the scenario observed with multiple myeloma, rapidly growing purely lytic lesions can be missed by BS. Another potential cause of transient false negative $\mathrm{BS}$ is the concomitant use of bisphosphonate. Demirkan et al. [25] reported the case of a breast cancer patient treated with alendronate for osteoporosis and a negative BS despite extensive bone metastases. A possible explanation could be a transient phenomenon of competition between alendronate and ${ }^{99 \mathrm{~m}} \mathrm{Tc}$-phosphonate in bone uptake and renal excretion. Therefore, to characterize equivocal findings observed by BS, other imaging tests such as XR, MRI or CT, and sometimes bone biopsies, may be necessary. In addition, due to its higher specificity, whole-body ${ }^{18} \mathrm{~F}$ FDG PET has been 
Table 1. Results from studies evaluating the role of BS as baseline staging test

\begin{tabular}{|c|c|c|c|c|c|}
\hline First author, year & Study design & Patients, $\mathrm{n}$ & $\begin{array}{l}\text { Positive } \\
\text { BS, \% }\end{array}$ & $\begin{array}{l}\text { Confirmation } \\
\text { of diagnosis }\end{array}$ & NNS \\
\hline Myers, 2001 [9] & $\begin{array}{l}\text { review of } 11 \text { studies } \\
\text { before } 1980\end{array}$ & 1,307 & 10.8 & - & 9.2 \\
\hline Monypenny, 1984 [42] & retrospective & 685 & 2.8 & - & 35.7 \\
\hline Kunkler, 1985 [43] & retrospective & 465 & 9.5 & - & 10.5 \\
\hline Khansur, 1987 [44] & retrospective & 265 & 10.6 & - & 9.4 \\
\hline Ciatto, 1988 [4] & retrospective & 2,450 & 0.9 & XR & 111.1 \\
\hline Coleman, 1988 [45] & retrospective & 1,155 & 4.0 & XR & 25.0 \\
\hline Piffer, 1988 [46] & retrospective & 204 & 0.5 & - & 200.0 \\
\hline Ahmed, 1990 [47] & retrospective & 389 & 6.2 & - & 16.1 \\
\hline Kennedy, 1991 [48] & retrospective & 84 & 3.6 & - & 27.8 \\
\hline Cox, 1992 [49] & prospective & 339 & 2.7 & - & 37.0 \\
\hline Brar, 1993 [50] & retrospective & 133 & 3.0 & XR & 33.3 \\
\hline Alcazar, 1995 [51] & retrospective & 190 & 6.3 & - & 15.9 \\
\hline Yeh, 1995 [52] & retrospective & 316 & 2.2 & XR, CT, MRI, biopsy & 45.4 \\
\hline Miner, 1998 [53] & retrospective & 544 & 8.0 & - & 12.5 \\
\hline Samant, 1999 [5] & retrospective & 143 & 10.5 & - & 9.5 \\
\hline Yip, 1999 [54] & retrospective & 208 & 12.0 & - & 8.3 \\
\hline Curigliano, 2001 [8] & retrospective & 765 & 0.5 & XR, CT, MRI & 200.0 \\
\hline Koizumi, 2001 [55] & retrospective & 5,538 & $2.1^{\mathrm{a}}$ & $\mathrm{XR}, \mathrm{CT}, \mathrm{MRI}$ & 47.6 \\
\hline Ravaioli, 2002 [10] & retrospective & 1,193 & 3.1 & CT, MRI & 32.2 \\
\hline Schneider, 2003 [12] & retrospective & 485 & 2.7 & $\mathrm{XR}, \mathrm{CT}$ & 37.0 \\
\hline Ho, $2005[40]$ & retrospective & 126 & 8.7 & XR, CT, MRI & 11.5 \\
\hline Lee, $2005[14]$ & retrospective & 1,939 & 1.4 & XR, CT, MRI & 71.4 \\
\hline Puglisi, 2005 [13] & retrospective & 412 & 6.3 & $\mathrm{XR}, \mathrm{CT}, \mathrm{MRI}$ & 15.9 \\
\hline Kasem, 2006 [56] & retrospective & 221 & 2.7 & XR, CT, MRI & 37.0 \\
\hline
\end{tabular}

$\mathrm{BS}=$ Bone scan; NNS = number of patients needed to screen by BS in order to detect one bone metastasis (calculated by dividing the total number of patients who underwent to BS, by the number of detected cases); XR = plain radiography; $\mathrm{CT}=$ computed tomography; $\mathrm{MRI}=$ magnetic resonance imaging.

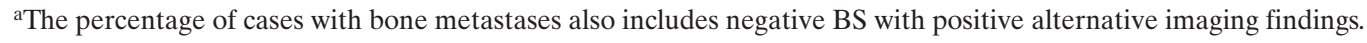

recently proposed as a useful tool in the process of differential diagnosis [26]. Alternatively, if the radiological and clinical doubt is not high, a follow-up strategy is often adopted by repeating BS in 4-6 months to evaluate for possible changes. According to the skeletal pattern at presentation (i.e. prevalence of osteolytic, osteoblastic, or mixed lesions), the different characteristics of imaging techniques to detect bone metastasis may result in peculiar diagnostic performance (figs. 1-3). In fact, besides the information on osteoblastic metabolism and bone turnover obtained with BS and bone SPECT, XR and CT allow to visualize bone structure, CT and MRI provide better analysis of tumor and bone marrow, whereas ${ }^{18} \mathrm{~F}$ FGD PET is able to detect tumor cells metabolism and metastatic bone marrow involvement. In particular, $\mathrm{XR}$ is less sensitive than BS since it detects the net results of bone resorption and repair. The likelihood of radiographic detection is higher if areas of absent density (osteolytic lesions) or sclerotic lesions (if osteoblastic component is more relevant) are present, whereas tumor cells growing in the marrow rather than in the cortex are usually missed by XR [27]. Of note, an osteolytic lesion (the most common presentation of bone metastases BC-related) is detectable on XR when $30-75 \%$ of normal bone mineral content is lost, becoming ap- parent with a several months' delay (up to 18 months) from the actual bone spread [20]. Therefore, according to the status of bone involvement, it is not rare to observe a positive-tonegative conversion and vice versa of $\mathrm{BS}$ and XR [28]. CT scan is superior to $\mathrm{XR}$ in determining the extent of cortical metastatic involvement depicting accurately the bone anatomy. Its use is limited to the study of particular areas that need to be further investigated on the basis of BS findings. MRI is effective in early detection of bone metastases since it visualizes bone marrow with high sensitivity (even though it does not provide detailed images of the cortical bone). Metastases usually originate from red marrow and then spread to the cortex, so MRI could detect bone lesions earlier than BS, but the relatively high cost limits its use as a metastases screening method. Moreover, differently to BS, MRI does not provide an assessment of the whole skeleton. Therefore, MRI is considered a complementary study when BS is not conclusive or in cases of discrepancies between symptoms and BS results. An added value of MRI is represented by the high-quality images of the spinal cord and epidural extension, particularly useful when a spinal cord compression is hypothesized. ${ }^{18} \mathrm{~F}$ FDG PET, owing to its ability to detect the metabolic activity of cells, yields superior accuracy in the diagnosis of bone mar- 
row involvement and bone metastases than BS, in particular for osteolytic lesions which have higher metabolic activity than osteoblastic ones (fig. 2) [26]. Hence, total body ${ }^{18}$ F FDG PET could overcome the lack of accuracy of BS other than providing a complete tumor staging [29].

Some studies show that the accuracy of BS can be improved by additional SPECT imaging [30]. Notably, use of SPECT to clarify 'hot spots' identified by BS revealed to be useful for distinguishing benign from malignant lesions, especially in sites that are extensively surrounded by soft tissue such as spine and pelvis $[18,30]$. More recently, new hybrid devices such as PET/CT and SPECT/CT were introduced with the aim of combining their ability to study function and morphology at the same time. This allows to fuse images and further increases accuracy of both techniques. (i.e. high sensitivity imaging of bone metabolism and high-resolution imaging of bone morphology) [31].

\section{Is Bone Scan Recommended as Baseline Procedure for Primary Breast Cancer?}

Since its introduction into the clinical practice in the late 1960s $[32,33]$, a large number of studies have been published on the value of $\mathrm{BS}$ as initial diagnostic test to detect the presence of skeletal metastases of $\mathrm{BC}$ at the time of primary presentation (table 1). However, the majority of these reports have suggested that the use of BS in the BC staging is of no benefit in the absence of symptoms or abnormal laboratory tests $[4,5$, 7-14]. These conclusions are based on the observation that the detection rate (i.e. the proportion of BS that were positive for metastases) is particularly low in asymptomatic patients with small primary tumors and/or without axillary lymph node involvement. Furthermore, the cost of the procedure is not negligible, and false positive results may generate unjustified anxiety and discomfort in some patients [34]. In addition, the costs of possible BS-induced complementary tests (e.g. MRI, $\mathrm{CT},{ }^{18} \mathrm{~F}$ FDG PET, bone biopsy) have to be considered. Accordingly, in view of cost-effectiveness analysis, a minimalist approach is suggested by many authors with the aim to save costs and to optimize the use of medical resources. In other words, BS as well as other baseline tests should be tailored to staging classification and symptoms at presentation in order to improve the pre-test probability in distant metastases detection $[34,35]$.

Notably, no official guidelines on preoperative or perioperative use of BS have been set out by the American Society of Clinical Oncology (ASCO). On the other hand, based on available scientific evidence, ASCO guidelines for breast cancer surveillance do not recommend serial employment of BS during follow-up [36]. According to National Comprehensive Cancer Network Practice Guidelines, BS is indicated in presence of localized symptoms or elevated alkaline phosphatase or if stage IIIA, whereas it is not recommended for surveillance [37]. Even though recognizing a low level of evidence (III, B), the European Society of Medical Oncology (ESMO) recommended the use of BS in patients with pathological N2 or T4 tumors or with laboratory signs or symptoms suspicious for the presence of bone metastases [38].

In 2001, the Breast Cancer Disease Site Group of the Cancer Ontario Practice Guidelines Initiative published their recommendation for baseline staging tests in primary $\mathrm{BC}$, including BS [9]. After careful analysis of the literature (from 1966 to 2000), group members recommended baseline BS in all women with pathological stage III tumors, whereas the test was judged not indicated for patients with intraductal and stage I disease. The cost-effectiveness of BS in stage II was the area of greatest controversy, especially because it was not clear if the rate of bone metastases detected in this group of patients is high enough to justify a routine use of the test in this target population. On the other hand, the interpretation of the literature on BS as staging procedure after a diagnosis of $\mathrm{BC}$ is impaired by the weak, mostly retrospective, design of the available studies. In particular, since the publication of first reports, several changes occurred on staging classification as well as on diagnostic and therapeutic management of BC. As a consequence, no reliable comparisons can be made among different studies and formal metanalysis of the data is precluded.

Interestingly, Lee et al. [14] examined 1,939 patients with primary $\mathrm{BC}$ and compared the detection rate of BS according to both the current American Joint Committee on Cancer (AJCC) staging system and the past 1988 edition. Stage reclassification by the 2003 system resulted in significant upstaging, especially for patients with stage II/III disease. Therefore, as expected after the observation of stage migration and on the basis of Will Rogers phenomenon, a decrease in the bone metastases rate was found for both stage II and III.

Another critical issue in comparing different results of the literature is the different approach used to confirm the diagnosis of bone metastasis after detection of suspicious hot spots by BS. Notably, the use of CT and MRI were reported only in the most recent publications. In addition, with the wide employment of mammographic screening, the percentage of small preclinical BC and the prevalence of metastatic disease inversely changed over time.

Overall, these observations may explain why older studies tended to report detection rates of BS that are higher than that found by most recent studies. Although a well conducted, randomized clinical trial could provide reliable evidence on the role of baseline BS in newly diagnosed BC [39], such a trial is not easy to carry out because of the large sample size and the long follow-up needed. Therefore, efforts to reduce unnecessary testing should be directed towards the identification of parameters that could improve the pre-test probability of BS. Interestingly, Ravaioli et al. [10] reported a statistically significant correlation between positive BS and increased alkaline phosphatase, CEA, and Ca 15.3 tumor marker values ( $\mathrm{p} \leq$ 0.001). Similarly, Puglisi et al. [13] found a marginally significant correlation $(\mathrm{p}=0.05)$ between high values of $\mathrm{Ca} 15.3$ and 
the diagnosis of bone metastases. However, the abovementioned results, obtained from retrospective analysis of small subgroups of patients, must be interpreted with caution. In addition, among parameters that are not included in tumor stage classification, Ho and Chan [40] reported that increasing age, a higher histopathological grading, and positive progesterone receptor status independently predict a positive BS status.

Apart from the issue of which patients could mostly benefit from baseline BS, another important unsolved question is when to perform the test (before or after surgery). Surgical planning and systemic therapies could in fact be revised after detection of bone metastases. Recently, an interesting study was published on the role of pre- and postoperative ${ }^{18} \mathrm{~F}$ FDG PET in determining a therapeutic impact in patients with clinically intermediate or high-risk newly diagnosed BC [29]. Notably, the authors suggested that ${ }^{18}$ F FDG PET has a substantial impact on treatment planning of individual patients and also on clinical and diagnostic workflows. To the best of our knowledge, no similar studies are available on the role of BS in influencing therapeutic decisions. However, simulation of different clinical scenarios may help to predict when the detection of bone metastases could have higher chances to modify the patient management, resulting in selection of alternative treatments. For example, patients with stage I-II BC in which needless breast surgery could be avoided in case of bone metastases documentation are also the group with the lowest likelihood to have a positive BS. Moreover, based on provocative results of a recent study, the uselessness of complete excision of primary $\mathrm{BC}$ in patients with metastatic bone disease at diagnosis has been questioned [41]. On the other hand, although the pre-test probability of BS is undoubtedly higher in patients with inoperable stage III tumors, the influence of a positive test on initial treatment planning could be paradoxically modest. In addition, it is intuitive that BS should be not recommended in all clinical circumstances in which the decision on treatment has a low likelihood to change in case of positive results, such as in presence of co-morbid illness or when the treatment with adjuvant intention does not differ from that with palliative intention (e.g. adjuvant hormonal therapy vs. hormonal therapy for metastatic disease limited to bone).

The aforementioned considerations notwithstanding, baseline BS may be useful for comparison with subsequent imaging findings during follow-up. Accordingly, it should be always required as part of clinical trials where the significance of staging tests is also to match up equivalent groups of the enrolled patients.

\section{Conclusions}

BS is still the most commonly used test to screen for skeletal metastases in patients with $\mathrm{BC}$, with the addition of SPECT views, if needed. New promising imaging techniques such as ${ }^{18} \mathrm{~F}$ FDG PET can certainly play a significant role in BC patients, especially in case of suspected extra-osseous extension of the disease or in case of symptomatic bone lesions despite a normal BS. It is worth to remember that skeletal lytic metastases may cause false negative BS results, but are highly ${ }^{18} \mathrm{~F}$ FDG avid.

In conclusion, a large number of studies exploring the role of BS in the baseline staging work-up suggest that its use is not cost-effective and should not be routinely recommended. In fact, even though caution is required when examining the literature, the majority of papers report a low detection rate in asymptomatic patients with early-stage disease. Accordingly, based on current guidelines, the use of BS as a staging procedure is considered appropriate if there is a high pre-test probability of bone metastases (i.e. pN2 or T4/pT4 breast cancer or suspicious symptoms or laboratory signs).

\section{References}

$>_{1}$ Scanlon EF, Oviedo MA, Cunningham MP, Caprini JA, Khandekar JD, Cohen E, Robinson B, Stein E: Preoperative and follow-up procedures on patients with breast cancer. Cancer 1980;46:977-979.

$\checkmark 2$ Feig SA: The role of new imaging modalities in staging and follow-up of breast cancer. Semin Oncol 1986;13:402-414.

3 Morrow M: What is the purpose of cancer staging? Breast 2006;15:1-2.

4 Ciatto S, Pacini P, Azzini V, Neri A, Jannini A, Gosso P, Molino A, Capelli A, Di Costanzo F, Pucciatti MA, Andreoli C, Santoro G, Farante G, Ciurli M, Costa A, Brignone G, Ravaioli A, Scarpellini M, Rosetti P, De Leo G, Punzo C, Oliva V: Preoperative staging of primary breast cancer: a multicenter study. Cancer 1988;61:1038-1040.

5 Samant R, Ganguly P: Staging investigations in patients with breast cancer: the role of bone scans and liver imaging. Arch Surg 1999;134:551-553.
6 Chen A, Carlson GA, Coughlin BF, Reed WP, Garb JL, Frank JL: Routine chest roentgenography is unnecessary in the work-up of stage I and II breast cancer. J Clin Oncol 2000;18:3503-3506.

7 Dillman RO, Chico S: Radiologic tests after a new diagnosis of breast cancer. Eff Clin Pract 2000;3: $1-6$.

8 Curigliano G, Ferretti G, Colleoni M, Marrocco E, Peruzzotti G, De Cicco C, Paganelli G, Goldhirsch A: Bone scan had no role in the staging of 765 consecutive operable T1-2N 0-1 breast cancer patients without skeletal symptoms. Ann Oncol 2001;12: 724-725.

$\checkmark$ Myers RE, Johnston M, Pritchard K, Levine M, Oliver T and the Breast Cancer Disease Site Group of the Cancer Care Ontario Practice Guidelines Initiative: Baseline staging tests in primary breast cancer: a practice guideline. CMAJ 2001;164:14391444.
10 Ravaioli A, Pasini G, Polselli A, Papi M, Tassinari D, Arcangeli V, Milandri C, Amadori D, Bravi M, Rossi D, Fattori PP, Pasquini E, Panzini I: Staging of breast cancer: new recommended standard procedure. Breast Cancer Res Treat 2002;72:53-60.

11 Gerber B, Seitz E, Muller H, Krause A, Reimer T, Kundt G, Friese K: Perioperative screening for metastatic disease is not indicated in patients with primary breast cancer and no clinical signs of tumor spread. Breast Cancer Res Treat 2003;82:29-37.

12 Schneider C, Fehr MK, Steiner RA, Hagen D, Haller U: Frequency and distribution pattern of distant metastases in breast cancer patients at the time of primary presentation. Arch Gynecol Obstet 2003;269:9-12.

13 Puglisi F, Follador A, Minisini AM, Cardellino GG, Russo S, Andreetta C, Di Terlizzi S, Piga A: Baseline staging tests after a new diagnosis of breast cancer: further evidence of their limited indications. Ann Oncol 2005;16:263-266. 
14 Lee JE, Park SS, Han W, Kim SW, Shin HJ, Choe KJ, Oh SK, Youn YK, Noh DY, Kim SW: The clinical use of staging bone scan in patients with breast carcinoma: reevaluation by the 2003 American Joint Committee on Cancer staging system. Cancer 2005;104:499-503.

$\checkmark 15$ Coleman RE, Rubens RD: The clinical course of bone metastases from breast cancer. Br J Cancer 1987;55:61-66.

16 Roodman GD: Mechanisms of bone metastasis. N Engl J Med 2004;350:1655-1664.

17 Mundy G: Metastatic bone disease; in Fogelman I (ed): Bone Remodelling and Its Disorders. London, Martin Dunitz,1995, pp. 104-122.

18 Hamaoka T, Madewell JE, Podoloff DA, Hortobagyi GN, Ueno NT: Bone imaging in metastatic breast cancer. J Clin Oncol 2004;22:2942-2953.

19 Morgan-Pakes JH: Metastases: mechanism, pathways, and cases. AJR 1995;164:1075-1082.

20 Krasnow AZ, Hellman RS, Timins ME, Collier BD, Anderson T, Isitman AT: Diagnostic bone scanning in oncology. Sem Nucl Med 1997;27:107-141.

21 O'Sullivan JM, Cook GJR: A review of the efficacy of bone scanning in prostate and breast cancer. Q J Nucl Med 2002;46:152-159.

-22 Cook GJ, Fogelman I: Skeletal metastases from breast cancer: imaging with nuclear medicine. Semin Nucl Med 1999;29:69-79.

23 Buscombe JR, Holloway B, Roche N, Bombardieri E: Position of nuclear medicine modalities in the diagnostic work-up of breast cancer. Q J Nucl Med Mol Imaging 2004;48:109-118.

24 Haubold-Reuter BG, Duewell S, Schilcher BR, Marincek B, von Schulthess GK: The value of bone scintigraphy, bone marrow scintigraphy and fast spin-echo magnetic resonance imaging in staging of patients with malignant solid tumours: a prospective study- Eur J Nucl Med 1993;20:1063-1069.

25 Demirkan B, Baskan Z, Alacacioglu A, Gorken IB, Bekis R, Ada E, Osma E, Alakavuklar M: False negative bone scintigraphy in a patient with primary breast cancer: a possible transient phenomenon of bisphosphonate (alendronate) treatment. Tumori 2005;91:77-80.

26 Byrne AM, Hill ADK, Skehan SJ, McDermott EW, O'Higgins NJ: Positron emission tomography in the staging and management of breast cancer. $\mathrm{Br} \mathrm{J}$ Surg 2004;91:1398-1409.

27 Gosfield E, III, Alavi A, Kneeland B: Comparison of radionuclide bone scans and magnetic resonance imaging in detecting spinal metastases. J Nucl Med 1993;34:2191-2198.

-28 Crippa F, Seregni E, Agresti R, Bombardieri E, Buraggi GL: Bone scintigraphy in breast cancer: a ten-year follow-up study. J Nucl Biol Med 1993; 37:57-61.
29 Klaeser B, Wiederkehr O, Koeberle D, Mueller A, Bubeck B, Thuerlimann B: Therapeutic impact of 2-[fluorine-18]fluoro-2-deoxy-D-glucose positron emission tomography in the pre- and postoperative staging of patients with clinically intermediate or high-risk breast cancer. Ann Oncol 2007;18: 1329-1334.

30 Langsteger W, Heinisch M, Fogelman I: The role of fluorodeoxyglucose, 18F-dihydroxyphenylalanine, $18 \mathrm{~F}$-choline, and $18 \mathrm{~F}$-fluoride in bone imaging with emphasis on prostate and breast. Sem Nucl Med 2006;36:73-92.

31 Horger M, Bares R: The role of single-photon emission computed tomography/computed tomography in benign and malignant bone disease. Semin Nucl Med 2006;36:286-294.

32 Galasko CSB: The detection of skeletal metastases for mammary cancer by gamma camera scintigraphy. Br J Surg 1969;56:757-764.

33 Gerber FH, Goodreau JJ, Kirchner PT, Fouty WJ: Efficacy of preoperative and postoperative bone scanning in the management of breast carcinoma. N Engl J Med 1977;297:300-303.

34 Lind DS: Breast cancer testing: what is appropriate? J Surg Oncol 2002;81:111-112.

35 Puglisi F: Bone scanning in lung cancer: pretest probability is of value. BMJ 2004;329:231.

36 Khatcheressian JL, Wolff AC, Smith TJ, Grunfeld E, Muss HB, Vogel VG, Halberg F, Somerfield MR, Davidson NE; American Society of Clinical Oncology: American Society of Clinical Oncology 2006 update of the breast cancer follow-up and management guidelines in the adjuvant setting. J Clin Oncol 2006;24:5091-5097.

37 NCCN Clinical Practice Guidelines in Oncology. Breast Cancer, version 2, 2007, www.nccn.org.

38 No authors listed: Primary breast cancer: ESMO Clinical Recommendations for diagnosis, treatment and follow-up. Ann Oncol 2007;18:ii5-ii8.

39 Tassinari D, Sartori S, Ravaioli A: Staging breast cancer. Is the evidence so evident? Ann Oncol 2001;12:1653-1654.

40 Ho YY, Chan YH: Predictors of a positive baseline bone scan in breast cancer. Australas Radiol 2005; 49:21-26.

41 Rapiti E, Verkooijen HM, Vlastos G, Fioretta G, Neyroud-Caspar I, Sappino AP, Chappuis PO, Bouchardy C: Complete excision of primary breast tumor improves survival of patients with metastatic breast cancer at diagnosis. J Clin Oncol 2006;24: 2743-2749.

42 Monypenny IJ, Grieve RJ, Howell A, Morrison JM: The value of serial bone scanning in operable breast cancer. Br J Surg 1984;71:466-468.
43 Kunkler IH, Merrick MV, Rodger A: Bone scintigraphy in breast cancer: a nine-year follow-up. Clin Radiol 1985;36:279-282.

44 Khansur T, Haick A, Patel B, Balducci L, Vance R, Thigpen T: Evaluation of bone scan as a screening wok-up in primary and local-regional recurrence of breast cancer. Am J Clin Oncol 1987;10:167-170.

45 Coleman RE, Rubens RD, Fogelman I: Reappraisal of the baseline bone scan in breast cancer. J Nucl Med 1988;29:1045-1049.

46 Piffer S, Amichetti M, Valentini A: Skeletal scintigraphy and physical examination in the staging of early breast cancer. Acta Oncologica 1988;27: 21-23.

47 Ahmed A, Glynne-Jones R, Ell PJ: Skeletal scintigraphy in carcinoma of the breast - a ten year retrospective study of 389 patients. Nucl Med Commun 1990;11:421-426.

48 Kennedy H, Kennedy N, Barclay M, Horobin M: Cost efficiency of bone scans in breast cancer. Clin Oncol 1991;3:73-77.

49 Cox MR, Gilliland R, Odling-Smee GW, Spence RA: An evaluation of radionuclide bone scanning and liver ultrasonography for staging breast cancer. Aust N Z J Surg 1992;62:550-555.

50 Brar HS, Sisley JF, Johnson RH Jr: Value of preoperative bone and liver scans and alkaline phosphatase in the evaluation of breast cancer patients. Am J Surg 1993;165:221-224.

51 Alcazar JL, Rolle A, Murcia JM: Bone scanning in preoperative staging of early breast cancer patients: should it be a routine procedure? Breast Dis 1995; 8:7-11.

52 Yeh KA, Fortunato L, Ridge JA, Hoffman JP, Eisenberg BL, Sigurdson ER: Routine bone scanning in patients with $\mathrm{T} 1$ and $\mathrm{T} 2$ breast cancer: a waste of money. Ann Surg Oncol 1995;2:319-324.

53 Miner TJ, Shriver CD, Jaques DP, Schutt DC: The department of Defense experience in perioperative testing for metastatic disease in patients with breast cancer. Breast J 1998;4:84-88.

54 Yip CH, Paramsothy M: Value of routine $99 \mathrm{mTc}$ MDP bone scintigraphy in the detection of occult skeletal metastases in women with primary breast cancer. Breast 1999;8:267-269.

55 Koizumi M, Yoshimoto M, Kasumi F, Ogata E: What do breast cancer patients benefit from staging bone scintigraphy? Jpn J Clin Oncol 2001;31: 263-269.

56 Kasem AR, Desai A, Daniell S, Sinha P: Bone scan and liver ultrasound scan in the preoperative staging for primary breast cancer. Breast J 2006;12: 544-548. 